\title{
Hippuric Acid as a Significant Regulator of Supersaturation in Calcium Oxalate Lithiasis: The Physiological Evidence
}

\author{
Stoyanka S. Atanassova ${ }^{1}$ and Ivan S. Gutzow ${ }^{2}$ \\ ${ }^{1}$ Department of Clinical Laboratory and Clinical Immunology, Medical University, "G. Sofiisky” Boulevard 1, 1431 Sofia, Bulgaria \\ ${ }^{2}$ Institute of Physical Chemistry, Bulgarian Academy of Sciences, 1113 Sofia, Bulgaria \\ Correspondence should be addressed to Stoyanka S. Atanassova; stoyana_atanassova@abv.bg
}

Received 2 April 2013; Revised 7 September 2013; Accepted 8 September 2013

Academic Editor: Seiichi Saito

Copyright (c) 2013 S. S. Atanassova and I. S. Gutzow. This is an open access article distributed under the Creative Commons Attribution License, which permits unrestricted use, distribution, and reproduction in any medium, provided the original work is properly cited.

\begin{abstract}
At present, the clinical significance of existing physicochemical and biological evidence and especially the results we have obtained from our previous in vitro experiments have been analyzed, and we have come to the conclusion that hippuric acid $\left(\mathrm{C}_{6} \mathrm{H}_{5} \mathrm{CONHCH}{ }_{2} \mathrm{COOH}\right)$ is a very active solvent of Calcium Oxalate $(\mathrm{CaOX})$ in physiological solutions. Two types of experiments have been discussed: clinical laboratory analysis on the urine excretion of hippuric acid (HA) in patients with CaOX lithiasis and detailed measurements of the kinetics of the dissolution of $\mathrm{CaOX}$ calculi in artificial urine, containing various concentrations of HA. It turns out that the most probable value of the HA concentration in the control group is approximately ten times higher than the corresponding value in the group of the stone-formers. Our in vitro analytical measurements demonstrate even a possibility to dissolve $\mathrm{CaOX}$ stones in human urine, in which increased concentration of HA have been established. A conclusion can be that drowning out $\mathrm{HA}$ is a significant regulator of $\mathrm{CaOX}$ supersaturation and thus a regulation of $\mathrm{CaOX}$ stone formation in human urine. Discussions have arisen to use increased concentration of HA in urine both as a solubilizator of $\mathrm{CaOX}$ stones in the urinary tract and on the purpose of a prolonged metaphylactic treatment.
\end{abstract}

\section{Introduction}

Calcium oxalate stones are the most common type of stones in urolithiasis in developed countries [1-3]. In addition, it is very important that the formation of such stones is caused by some gastrointestinal diseases [4].

Two main factors characterize a calcium oxalate $(\mathrm{CaOX})$ calculus as the most important stone formed in our lives: on the one hand, this fact is true, because of its frequency of occurrence and a high rate of recurrence, but on the other hand, it is due to the lack of a significant therapeutic effect of a dietary or a pharmacological attack. Despite a number of promising hypotheses, the pathogenic mechanism of intrarenal calcium oxalate stone formation remains, in many aspects, obscure. We must also say that, based on the dominant role of hypercalciuria in the pathogenesis of calcium oxalate stone formation $[5,6]$, the therapeutic efforts that have been made, prove neither clinically nor scientifically to be well applied.
The problem of calculating the supersaturation in urine (i.e., the driving force of this particular case of phase transformation) and the problem of finding out the possible natural or pharmaceutical regulators of this driving force, in the process of investigating the kinetics of crystal nucleation and growth, as well as in the investigation of the kinetics of the dissolution of already existing stones, appears to be of utmost significance.

Although the relative effect of a number of constituents of human urine on the solubility of $\mathrm{CaOX}$ has been determined in simple salt solutions, the exact combination of the factors that are responsible for variations in $\mathrm{CaOX}$ solubility in urine is very yet insufficiently known. Bearing this in mind, changes in the urinary oxalate ion concentration are more likely to decrease the supersaturation of urine than similar changes in the urine calcium concentration. Moreover, we know that the amount of oxalate excreted in urine depends on endogenous production, intestinal absorption, dietary intake, and renal transport. The endogenous production of oxalate, 
predominantly derived from the metabolism of glyoxylate and ascorbates, contributes significantly to the amount of oxalate that is excreted in urine [7-9]. We also know that it is possible to influence oxalate endogenous production by drug administration. In this connection, a number of clinical studies have demonstrated that the intake of certain drugs, which are essentially benzoate derivatives, leads to an increase in $\mathrm{CaOX}$ solubility $[10,11]$. The main route of biotransformation of benzoic acid in human individuals is conjugation with glycine, which results in the formation of hippuric acid (HA) [12-14].

In previous researches (see $[15,16])$, we have found out that one of the normal physiological constituents of human urine-hippuric acid $\left(\mathrm{C}_{6} \mathrm{H}_{5} \mathrm{CONHCH}_{2} \mathrm{COOH}\right)$-is, in fact, a complex forming physiological solvent of calcium oxalate. Our in vitro experiments showed that in the presence of $\mathrm{HA}$, the solubility of $\mathrm{CaOX}$ increases considerably and that in physiological solutions, in which HA is in concentrations approximately five to six times over its normal physiological concentration in urine (5 to $14 \mathrm{mMol} / 24 \mathrm{~h}$, according to the data presented by Boshev as given in [17]), the supersaturation in the system decreases significantly. These results, an account of which is given in $[15,16]$, are most meaningful from a physiological point of view, considering the well known fact that the increase of the concentration of HA in urine can be provoked by the per os administration of benzoic acid derivatives. This circumstance is, in fact, used in Quick's well known test of liver function $[14,18]$. This test reflects on the metabolism of aromatic complexes in the human organism and it is a demonstration of the long ago established fact that HA is the end product of the detoxification of aromatic complexes in human individuals.

It has been proven in recent years that the supersaturation in urine is determined not so much by the concentration of ions, constituting the concrements, but rather more by the presence or absence of complex forming ions in urine. This has been evident since Hammarsten's classic studies [19], according to which many ions, such as $\mathrm{Mg}^{2+}$, or citrate ions, which are also normally present in urine, increase the solubility of $\mathrm{CaOX}$ in aqueous solutions by forming complexes with either the $\mathrm{Ca}^{2+}$ or the $\mathrm{C}_{2} \mathrm{O}_{4}{ }^{2-}$ ions. Thus, $\mathrm{Mg}^{2+}$ and citric ions are to be considered as the two regulators of supersaturation in urine, concerning $\mathrm{CaOX}$ precipitation. However, the oral administration of these two complexing agents does not lead to encouraging clinical results, as they undergo metabolization in the human organism. From our already quoted investigations $[15,16]$, it follows that the concentration of HA also determines, essentially, the solubility of $\mathrm{CaOX}$ and that this substance may be the third and even most significant biological regulator of $\mathrm{CaOX}$ supersaturation in human urine.

Up to now, no biological or biochemical analysis has been performed concerning the possible correlation between HA concentration in urine and the inclination to calcium oxalate calculosis. The experimental investigations mentioned above and obtained in our in vitro experiments on the dissolution of $\mathrm{CaOX}$ in physiological solutions, containing an increased concentration of HA, necessitated such a generalized physiological analysis and the results of which are given below.

\section{Patients and Methods}

Two types of experiments were performed in the framework of our investigation.

(1) Clinical laboratory analysis on the concentration of $\mathrm{HA}$ in urine and the amount of total urine excretion of $\mathrm{HA}$ in patients with $\mathrm{CaOX}$ stones, as well as, in a healthy control group; and (2) an investigation on the kinetics of the dissolution of $\mathrm{CaOX}$ calculi in physiological solutions, containing various concentrations of HA.

\subsection{Patients Studied}

2.1.1. Stone Formers (SFs). 56 patients ( 30 men and 26 women), whose age ranged from 14 to 65 years, at the beginning of the disease, and who had had their calcium oxalate renal calculi removed (spontaneously, by surgery or through extracorporeal lithotripsy (ESWL)). Each patient had a known clinical history of his disease, including data for episodes of a renal colic and of concrements elimination, real urolithiasis in their families, the presence of metabolic disorders, and so forth. During the conduction of the study, the patients were on free mode and diet and with a fully compensated renal function. They did not report any liver disease. All investigated patients were hospitalized in the Clinic of the Department of Urology at the Medical University, Sofia.

2.1.2. Controls. 15 healthy subjects who had never had any urological and hepatic trouble.

2.1.3. Methods. A 24-hour urine collection was obtained from each patient. During the period of urine collection, specimens were refrigerated and aliquots of the 24-hour volume sample were immediately frozen until analyzed. The volume of urine in every sample was recorded on completion of the collection and $\mathrm{pH}$ was measured by using a glass electrode $\mathrm{pH}$-meter.

The calcium, oxalate, and other substances, such as creatinine, magnesium, phosphorous, uric acid, were also determined. All citied substances were measured by automated known spectrophotometry and colorimetric analysis. The urine levels of oxalates were evaluated by enzymatic method [20].

Amino acid contents (hippuric acid, glycine, serine, and so forth) of the collected samples were determined using a Hewlett Packard HPLC 1050 instrument (high-performance liquid chromatography), coupled to a fluorescence detector. Ethyl alcohol was added to urine specimens to allow the precipitation of proteins and the extraction of free amino acids. An automated precolumn orthophtaldehyde derivation procedure was employed. Separations were done using a reversed-phase column (Waters Corp). Amino acid concentration of the samples was determined in comparison to the values obtained from a standard curve prepared for each amino acid.

2.2. Statistical Analysis. Statistical analysis of the data obtained from both the SF patients and from the control 
group was performed using Student $t$-test, to establish the significance of the difference between mean values. All results were expressed as a mean \pm SEM and differences were considered significant if $P<0.05$.

\subsection{Dissolution of CaOX Concrements with Hippuric Acid (HA): In Vitro Experiments}

2.3.1. Instrumental Techniques. The experiments on the kinetics of the dissolution of $\mathrm{CaOX}$ renal calculi were performed in Jena glass round bottom flasks thermostated at $25^{\circ} \mathrm{C}$. The volume of the studied solution was $1000 \mathrm{~mL}$ and it was stirred $(\sim 200 \mathrm{rpm})$ by an electromagnetic stirrer. The Archimedean weight $G(t)$ of the samples of CaOX calculi, put in a platinum net basket and suspended to a torsion balance, was continuously measured with a sensitivity of $\pm 0.5 \mathrm{mg}$ (see $[15,16])$.

The CaOX calculi used had been formed in the urinary tract and eliminated spontaneously by the patients. The calculi were selected to have a weight of 100 to $200 \mathrm{mg}$ and to be of identical mineral composition, mainly $\mathrm{CaC}_{2} \mathrm{O}_{4} \cdot 2 \mathrm{H}_{2} \mathrm{O}$ (weddellite). The composition of the calculi was checked by polarized light microscopy and thermogravimetry (DTG).

We employed two different types of aqueous solutions, mimicking urine $[20,21]$, with our solvent (HA) introduced in several different concentrations.

The physic-chemical formalism of the kinetics of dissolution of kidney stones has been developed, in details, in our paper [15]. One can see that simple formulae can be obtained, describing the effect of complex forming agents (present in the solution at various concentrations) on supersaturation, solubility, and growth velocity of $\mathrm{CaOX}$ crystals growing or dissolving in a solution, resembling human urine. It can be shown that if we introduce an increasing concentration $C_{\mathrm{H}}$ (e.g., HA) of a $\mathrm{Ca}^{2+}$-binding complex forming agent, having a solubility constant $K_{\mathrm{H}}$ into the solution, a linear dependence between the solubility $S_{\mathrm{H}}$ and $\mathrm{C}_{\mathrm{H}}$ for $\mathrm{Ca}^{2+} \gg \mathrm{C}_{2} \mathrm{O}_{4}{ }^{2-}$ can be predicted by

$$
S_{\mathrm{H}} \approx S_{\mathrm{o}} \cdot\left(1+\frac{K_{\mathrm{H}} C_{\mathrm{H}}}{\alpha^{\prime}}\right),
$$

where $\alpha^{\prime}$ is the $\alpha$-factor in the absence of the complex forming agent $\mathrm{H}$ (here indicating hippuric acid).

Thus, the dependence of the supersaturation $\Delta \mu$ on $C_{\mathrm{H}}$ for the physiologically significant case $\mathrm{Ca}^{2+} \gg \mathrm{C}_{2} \mathrm{O}_{4}{ }^{2-}$, determining the supersaturation in urine is

$$
\Delta \mu \approx \Delta \mu_{\mathrm{o}}-\left(\frac{1}{2}\right) \cdot \ln \left(\frac{K_{\mathrm{H}} C_{\mathrm{H}}}{\alpha^{\prime}}\right)
$$

where $\Delta \mu_{\mathrm{o}}$ is the supersaturation in respect to the CaOXprecipitation without HA added.

It is also of significant interest that in the case of the dissolution of $\mathrm{CaOX}$-concrements in the presence of a fixed initial concentration of $\mathrm{CaOX}$ (or-which in the case of $\mathrm{Ca}^{2+} \gg \mathrm{C}_{2} \mathrm{O}_{4}{ }^{2-}$ is the same-in the presence of constant concentration $C_{o}{ }^{*}$ of oxalic anions $\mathrm{Ca}^{2+}$ ) we have to rewrite (1) as follows:

$$
S_{\mathrm{H}} \approx S_{\mathrm{o}}\left(1+\frac{K_{\mathrm{H}} C_{\mathrm{H}}}{\alpha^{\prime}}\right)-\mathrm{C}_{\mathrm{o}}^{*} .
$$

Thus, a plot of $S_{\mathrm{H}}$ versus $C_{\mathrm{H}}$ should result in a straight line with a slope of $-S \cdot K_{\mathrm{H}} / \alpha^{\prime}$ cutting from the ordinate axis a segment $S_{\mathrm{H}}(0)=S-\mathrm{C}_{\mathrm{o}}{ }^{*}$. In this way, both $S_{\mathrm{H}}$ and $K_{\mathrm{H}}$ can be determined at a known value of $\alpha$ (according to data in Robertson et al. [22], $\alpha^{\prime}$ in human urine is approximately 2).

Thus, depending on the concentration $C_{\mathrm{H}}$, that is, on the sign of $\Delta \mu$ (i.e., $\Delta \mu<0$ during growth, $\Delta \mu<0$ during dissolution), growth or dissolution of $\mathrm{CaOX}$ concrements can be achieved simply by changing the concentration $C_{H}$ of the hippuric acid added.

\section{Results}

3.1. Clinical Laboratory Data. Table 1 shows reports by our laboratory on the urinary excretion of calcium, oxalate, creatinine, and others responsible for $\mathrm{CaOX}$ crystallization substances.

Mainly, urine concentrations of calcium and oxalate are responsible for calcium oxalate urine supersaturation, according to leading researchers $[19,22]$. However, given the complexity of the pathogenesis of $\mathrm{CaOX}$ renal calculosis, the mean values of renal calculosis reagents (calcium $\left[\mathrm{Ca}^{2+}\right]$ and oxalate $\left[\mathrm{C}_{2} \mathrm{O}_{4}{ }^{2-}\right]$ ) are not expected to be elevated in all analyzed cases. This is confirmed by our results. Due to the dispersion of the data, the average values of these indicators are within the accepted norms.

Only $10 \%$ of the patients have urinary calcium levels above $7.5 \mathrm{mMol} / 24 \mathrm{~h}$ (which is the upper limit of normal ranges [17]), but $39 \%$ of them have hyperoxaluria (oxalate above $0.45 \mathrm{mMol} / 24 \mathrm{~h}$, according to [20]).

Table 2 shows the urine excretion $(\mu \mathrm{mol} / 24 \mathrm{~h})$ of amino acids [23], mentioned above, in the groups of SF patients and controls. A mathematical estimation of the deviation from the observation over amino acids in patients has been made. It turned out that in the group of SFs, the investigated amino acid excretions were significantly decreased about $20 \%$ for serine and about $40 \%$ for Lysine. About $75 \%$ of the SFs showed also an excretion of HA lower than $5.6 \mathrm{mMol} / 24 \mathrm{~h}$.

3.2. Data of In Vitro Experiments. The solubility of CaOX in pure water at $25^{\circ} \mathrm{C}$ is about $4 \mathrm{mg} / \mathrm{L}\left(3,1 \cdot 10^{-5} \mathrm{Mol} / \mathrm{L}\right)$ according to our results in $[15,16]$.

The solubility of calcium oxalate in artificial urine with zero supersaturation is considerably increased $\left(8,7 \cdot 10^{-5}\right.$ $\mathrm{mol} / \mathrm{L}$ ) compared to its solubility, mentioned above, in pure water. This fact is due to the presence of complex ions $\left(\left[\mathrm{Mg}^{2+}\right]\right.$, citrate ions, etc. $)$ in this solution, as predicted by their stability constant $\left(\alpha_{i}\right)$, which is known from the analytical chemistry [24]. When HA is introduced into the same physiological solution, a dramatic change in solubility (up to $66 \cdot 10^{-5} \mathrm{~mol} / \mathrm{L}$ ) is observed, as shown in Figure 1 .

A similar effect of HA is also seen in artificial urine in which distinct supersaturation (due to the presence of 
TABLE 1: Urinary excretion of inorganic components and some trace elements in patients with CaOX calculosis.

\begin{tabular}{|c|c|c|c|c|}
\hline & $\begin{array}{c}\text { Data, according } \\
{[17]}\end{array}$ & $\begin{array}{l}\text { Controls } \\
\mathrm{mMol} / 24 \mathrm{~h}\end{array}$ & $\begin{array}{l}\text { Stone-formers } \\
\mathrm{mMol} / 24 \mathrm{~h}\end{array}$ & $P$ \\
\hline Calcium & $2.5-7.5$ & $3.9 \pm 1.9$ & $5.6 \pm 2.1$ & $P<0.05$ \\
\hline Oxalate & 0.45 & $0.3 \pm 0.17$ & $0.46 \pm 0.25$ & $P<0.001$ \\
\hline Phosphorous & $10.9-32.3$ & $15.0 \pm 10.4$ & $19.2 \pm 9.2$ & $P<0.05$ \\
\hline Uric acid & $1.19-4.16$ & $1.9 \pm 0.7$ & $2.3 \pm 1.5$ & $P<0.05$ \\
\hline Creatinine & $\begin{array}{l}\text { 오 } 8.8-17.6 \\
\text { 우 } 5.3-13.2\end{array}$ & $10.4 \pm 5.2$ & $11.8 \pm 6.1$ & $P<0.05$ \\
\hline Magnesium & 7.1-11.7 & $5.1 \pm 1.9$ & $3.9 \pm 0.9$ & $P<0.05$ \\
\hline Volume, mL & $1000 \pm 1500$ & $1490 \pm 350$ & $1050 \pm 300$ & $P<0.001$ \\
\hline $\mathrm{pH}$ & $6.0-6.1$ & $6.0 \pm 0.4$ & $6.1 \pm 0.3$ & NS \\
\hline
\end{tabular}

$(P)$ : statistically different from controls.

TABLE 2: Mean \pm SEM values $(\mu \mathrm{mol} / 24 \mathrm{~h}$ ) of urinary amino acids in controls and in the SFs.

\begin{tabular}{lccc}
\hline $\begin{array}{l}\text { Amino acids } \\
\text { x. }[\mu \mathrm{mol} / 24 \mathrm{~h}]\end{array}$ & $\begin{array}{c}\text { Data, } \\
\text { according }[23]\end{array}$ & Controls & Stone-formers \\
\hline Serine (Ser) & 584 & $392.3 \pm 92.3$ & $240.6 \pm 202.6^{*}$ \\
$\begin{array}{l}\text { Glycine (Gly) } \\
\text { Hippuric acid }\end{array}$ & 984 & $1064.7 \pm 426.1$ & $841.5 \pm 439.9$ \\
(HA), mMol/24 & $5.6-14[17]$ & $19.5 \pm 8.4$ & $1.9 \pm 0.6^{*}$ \\
\hline
\end{tabular}

${ }^{*}(P<0.001)$ statistically different from controls.

normal concentration of $\left[\mathrm{Ca}^{2+}\right]$ and medium concentration of $\left[\mathrm{C}_{2} \mathrm{O}_{4}{ }^{2-}\right]$ ions) has been introduced (curves 2 and 3 , Figure 1). In accordance to (1), a linear dependence of the solubility $C_{H}$ is observed for each series of measurements, in which three different supersaturation values (zero, medium and normal) have been established.

The effect of the increasing concentration of hippuric acid on the solubility of $\mathrm{CaOX}$-concrements is clearly evident; the initially supersaturated solutions are transformed into undersaturated systems. The effect of the presence of $\left[\mathrm{Ca}^{2+}\right]$ in the course of the straight lines 2 and 3 in Figure 1, as compared to the non- $\mathrm{Ca}^{2+}$ case (line 1 in the same figure) is to be noted. A sharp decrease in the slope of lines 2 and 3 is observed, too. Since the two solutions have the same $\left[\mathrm{Ca}^{2+}\right]$ concentration, curves 2 and 3 are parallel, as expected from the formalism, as discussed above (see also [15]).

\section{Discussion}

The majority of urinary calculi found in patients with urolithiasis are predominantly of calcium oxalate composition. Calcium and oxalate are the two urine substances responsible for $\mathrm{CaOX}$ crystallization. The results of our study indicate that $\mathrm{CaOX} \mathrm{SF}$ patients are different from normal patients in regards to urinary oxalate excretion; about $39 \%$ of SFs excrete more oxalate than controls $(P<0.05)$ (see Table 1 and [20]). Only $10 \%$ of them have hypercalciuria. Few of them $(4 \%)$, however, show hypercalciuria and hyperoxaluria together.

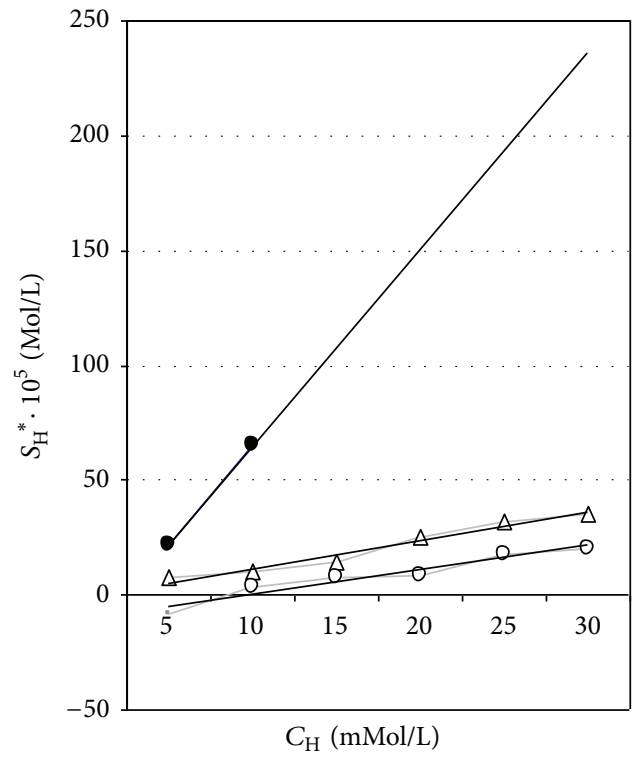

FIGURE 1: Solubility of calcium oxalate calculi in artificial urine as a function of hippuric acid concentration in three physiological solutions, according to the author's in vitro experiments. $\bullet$ solubility in zero saturation artificial urine (curve 1$), \triangle$ solubility in artificial urine with lower saturation $-2,5 \mathrm{mmol} / \mathrm{L} \mathrm{Ca}^{2+}$ and $0,02 \mathrm{mmol} / \mathrm{L}$ $\mathrm{C}_{2} \mathrm{O}_{4}{ }^{2-}$ ions (curve 2), and $\circ$ solubility in artificial urine with "normal" saturation as in "standard" human urine $-2,5 \mathrm{mmol} / \mathrm{L} \mathrm{Ca}^{2+}$ and $0,2 \mathrm{mmol} / \mathrm{L} \mathrm{C}_{2} \mathrm{O}_{4}{ }^{2-}$ ions (curve 3).

It seems natural to expect that the reduction of the total amount of oxalate that is present in the urine of SFs could give the key to prevention or to successful treatment of $\mathrm{CaOX}$ urolithiasis. It is known, that approximately $60 \%$ of urinary oxalate stones are derived from the endogenous metabolism of glycine, glycolate, and hydroxyproline, and $25 \%$ to $30 \%$ are the end product of dietary ascorbate metabolism. The remaining $10 \%$ to $15 \%$ come from dietary oxalate intake [ 8 , $25,26]$. However, there is no means of decreasing endogenous oxalate production. Nevertheless, one may assume that decreasing exogenous oxalate intake may lessen urinary oxalate levels. 
TABLE 3: Hippuric acid as a solvent of calcium oxalate: comparison with classical complex-forming agents.

\begin{tabular}{lcccccc}
\hline Ligand & Complex-former & Solution & $T^{\circ} \mathrm{C}$ & $\mathrm{pH}$ & $K_{i}, \mathrm{~L} / \mathrm{mol}$ & $\mathrm{Reference}$ \\
\hline $\mathrm{Na}-$ EDTA & $\mathrm{Ca}^{2+}$ & Physiological solution & 25 & 7,0 & $5,0 \cdot 10^{5}$ & {$[15]$} \\
$\mathrm{Mg}^{2+}$ & $\mathrm{C}_{2} \mathrm{O}_{4}{ }^{2-}$ & $0,3 \mathrm{M} \mathrm{NaCl}$ & 37 & - & $5,6 \cdot 10^{3}$ & {$[19]$} \\
$\mathrm{Mg}^{2+}$ & $\mathrm{C}_{2} \mathrm{O}_{4}{ }^{2-}$ & $0,3 \mathrm{M} \mathrm{NaCl}$ & 25 & 5,0 & $4,0 \cdot 10^{3}$ & {$[15]$} \\
Citric anion & $\mathrm{Ca}^{2+}$ & Pure water & 25 & - & $5,0 \cdot 10^{2}$ & {$[22]$} \\
Hippuric acid & $\mathrm{Ca}^{2+}$ & Zero saturated artificial urine & 25 & 5,5 & $7,0 \cdot 10^{3}$ & {$[15]$} \\
\hline
\end{tabular}

Detailed analysis performed in our previous study [15] indicates that HA is comparable, in its solubility effect, to the best known classical complex binders of $\left[\mathrm{Ca}^{2+}\right]$ or $\left[\mathrm{C}_{2} \mathrm{O}_{4}{ }^{2-}\right]$ ions in urine, that is, $\left[\mathrm{Mg}^{2+}\right]$ and citrate anions. This can be seen from Table 3, in which the stability constant $K_{\mathrm{H}}$ of hippuric acid calculated according to our results (Figure 1 and (1)) is compared to $K_{i}$-values of $\left[\mathrm{Mg}^{2+}\right]$, Na-EDTA, and other known complex formers of $\mathrm{CaOX}$.

We have found that the mechanism of dissolution of $\mathrm{CaOX}$ calculi follows the Nernst model of a diffusion limited process as it is discussed in details in $[15,16]$.

At the same time, there is also a very a significant difference in the urinary HA concentration $(P<0.001)$ between both groups (see Table 1). Thus, it turns out that patients with oxalate stones generally excrete less HA than normal patients do. These results are meaningful from a physiological point of view considering the well-known fact that urinary HA excretion could be increased by oral administration of benzoic acid (BA) derivatives or salicylates. Moreover, the renal excretion of HA is not limited by the capacity of the renal tubular transport system, even at the highest excretion level obtained after administration of benzoates.

Sufficient data is available, confirming that the presence of $\mathrm{HA}$ in urine is a biological marker for the presence of organic aromatic compounds, for example, for benzoic or toluene exposure. Part of the toluene absorbed is eliminated by the exhaled breath, but a large percentage is oxidized in the organism to BA, conjugated with glycine, and excreted as HA in urine $[12,27,28]$ according to the chemical reaction given below

$$
\mathrm{C}_{6} \mathrm{H}_{5} \mathrm{COOH}+\mathrm{H}_{2} \mathrm{NCH}_{2} \mathrm{COOH}=\mathrm{C}_{6} \mathrm{H}_{5} \mathrm{CONHCH}_{2} \mathrm{COOH}+\mathrm{H}_{2} \mathrm{O}
$$

$$
\text { Benzoic acid Glycine Hippuric acid (HA) }
$$

Therefore, a high level of urinary HA may be achieved by the intake of BA. As a food preservative, BA (or sodium benzoate) is added to pickles, soft drinks, soya sauce, syrup, and caviar [28]. Besides, BA is naturally present in many fruits and vegetables, especially cranberries, prunes, and in coffee beans [29]. Sodium benzoate is also the constituent of several classical medicines (e.g., cough syrups). The origin of the increased presence of HA in human urine is presumably in many cases due to the BA present in the fruits mentioned above and also from the addition of benzoate preservatives to food. Along with this exogenous HA, an endogenous excretion should be considered too. It is known that HA may be bacteriostatic for Escherichia coli in concentration of 1 to $2 \mathrm{mg} / \mathrm{mL}[30,31]$. Last but not least, any of the paths

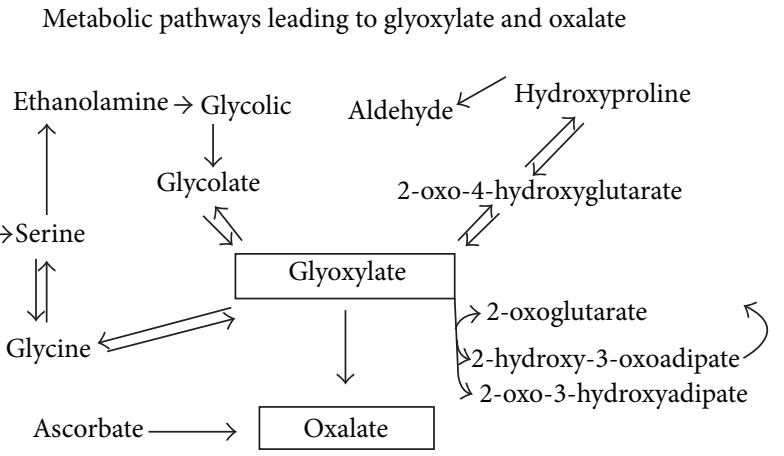

FIgURE 2: Metabolic pathway of oxalic acid.

mentioned above might exert an influence on the metabolic pathway of oxalic acid in the human organism (Figure 2).

As benzoates bind glycine in the liver, it is expected that the glycine-glyoxylate-oxalate link can be influenced by moving the equilibrium to a decreased level of the endogenous oxalate.

It is reasonable to assume that drug biotransformation interaction in the human organism, connected to the simultaneous conjugation of BA with glycine, could be a promising way for the development of future therapy methods for patients with $\mathrm{CaOX}$ calculi. We would like to add the possibility, we first mentioned in previous publications [15, 16], for the biological importance, which the multilateral role of HA output in the urine of patients with $\mathrm{CaOX}$-lithiasis could have as a Ca complex-forming agent.

In assessing the efficiency of HA as an eventual clinical solvent of $\mathrm{CaOX}$ calculi, one should also bear in mind that in the renal tract some conditions prevail, (continuous flushing of the calculus with fresh urine) under which the time necessary for the dissolution effect will be much shorter, as it is determined by the initial value of the dissolution rate. This possibility we confirmed in in vitro experiments with $\mathrm{CaOX}$ concrements, performed in confined volume and at physiological flow conditions, which correspond to a possible in vivo experiment in a human kidney pelvis. (see [32]).

Not only does it even seem that $\mathrm{HA}$ is the natural regulator of $\mathrm{CaOX}$ supersaturation in human urine, but it also appears to be such a regulator in mammal urine, in general. This follows from other known experimental findings on the very low frequency of calcium oxalate stone formation in herbivorous mammals [15]. The concentration of HA in mammal urine is, as a rule, considerably higher than its level in human urine. A classical and well-studied case in this 
respect gives the urine of horses (from where Justus von Liebig derived the name of the hippuric acid, many years ago).

Taking into account the metabolism of benzoic acid and its salts, as described above, a good alternative for metaphylaxis of the CaOX precipitation of nutrients would be added to the sodium benzoate. According to the so-called hepatic sample of Quick [14], taking 4 gr of sodium benzoate with tea, leads to separation of 6 gr of hippuric acid. Sodium benzoate is found in many berries, some formulations, and so forth, so it is not difficult to raise the urinary excretion and to establish an appropriate diet or medication.

One should expect that by administering and applying benzoic acid, for a short period of time, a considerable higher concentration of HA in stone formers with $\mathrm{CaOX}$ calculi, corresponding to the physiological norm of this substance in urine, could be and is in fact achieved. Thus, a negative supersaturation in respect to $\mathrm{CaOX}$-precipitation, and even the direct dissolution of $\mathrm{CaOX}$ calculi situated in the kidney pelvis, or elsewhere in the urinary tract, could be expected. One proof of this is achieved by our in vitro results of solubility of about $30 \mathrm{mMol} / \mathrm{L}$ stone.

The role and influence of drugs, containing benzoic acid derivatives which may provoke such effects, could be of great importance to a future medication. The amount of benzoates in a drug treatment will be the subject of future research. However, the important fact is that the salts of benzoic acid are contained in a number of berries and it may advantageously be applied as an appropriate diet for the prevention of $\mathrm{CaOX}$ nucleation.

\section{References}

[1] A. Ramello, C. Vitale, and M. Marangella, "Epidemiology of nephrolithiasis," Journal of Nephrology, vol. 13, no. 3, supplement, pp. S45-S50, 2000.

[2] M. Amato, M. L. Lusini, and F. Nelli, "Epidemiology of nephrolithiasis today," Urologia Internationalis, vol. 72, no. 1, pp. $1-5,2004$

[3] A. Trinchieri, C. Castelnuovo, R. Lizzano, and G. Zanetti, "Calcium stone disease: a multiform reality," Urological Research, vol. 33, no. 3, pp. 194-198, 2005.

[4] F. Grases, A. Costa-Bauza, and R. M. Prieto, "Renal lithiasis and nutrition," Nutrition Journal, vol. 5, no. 1, article 23, 2006.

[5] C. Y. C. Pak, "Hypercalciuric calcium nephrolithiasis," in Urolithiasis: A Medical and Surgical Reference, M. I. Resnick and C. Y. C. Pak, Eds., pp. 79-88, W. B. Saunders, Philadelphia, Pa, USA, 1990.

[6] J. M. Baumann, B. Affolter, U. Caprez, and U. Henze, "Calcium oxalate aggregation in whole urine, new aspects of calcium stone formation and metaphylaxis," European Urology, vol. 43, no. 4, pp. 421-425, 2003.

[7] R. G. Hahn and M. Sikk, "Glycine loading and urinary oxalate excretion," Urologia Internationalis, vol. 52, no. 1, pp. 14-16, 1994.

[8] N. Fituri, N. Allawi, M. Bentley, and J. Costello, "Urinary and plasma oxalate during ingestion of pure ascorbic acid: a reevaluation," European Urology, vol. 9, no. 5, pp. 312-315, 1983.

[9] A. W. Williams and D. M. Wilson, "Dietary intake, absorption, metabolism, and excretion of oxalate," Seminars in Nephrology, vol. 10, no. 1, pp. 2-6, 1990.
[10] J. N. Lange, K. D. Wood, J. Knight, D. G. Assimos, and R. P. Holmes, "Glyoxal formation and its role in endogenous oxalate synthesis," Advances in Urology, vol. 81, pp. 9202-9205, 2012.

[11] I. F. Ghalayini, M. A. Al-Ghazo, and M. N. A. Harfeil, "Prophylaxis and therapeutic effects of Raspberry (Rubus idaeus) on renal stone formation in Balb/c mice," International Brazilian Journal of Urology, vol. 37, no. 2, pp. 259-266, 2011.

[12] L. P. Amsel and G. Levy, "Drug biotransformation interactions in man-II. A pharmacokinetic study of the simultaneous conjugation of benzoic and salicylic acids with glycine," Journal of Pharmaceutical Sciences, vol. 58, no. 3, pp. 321-326, 1969.

[13] L. D. Pagnotto and L. M. Lieberman, "Urinary hippuric acid excretion as an index of toluene exposure," American Industrial Hygiene Association Journal, vol. 28, no. 2, pp. 129-134, 1967.

[14] A. Quick, “The conjugation of benzoic acid in man," Journal Biological Chemistry, vol. 92, pp. 65-68, 1931.

[15] I. Gutzow, S. Atanassova, and G. Budevsky, "Kinetics of dissolution of calcium oxalate calculi in physiological solutions containing hippuric acid," Crystal Research \& Technology, vol. 26, no. 5, pp. 533-554, 1991.

[16] I. Gutzow, S. Atanassova, G. Budevsky, and K. Neykov, "Solubility, inhibited growth and dissolution kinetics of calcium oxalate crystals in solutions, containing hippuric acid," Urological Research, vol. 21, no. 3, pp. 181-185, 1993.

[17] N. Boshev, “The biological constants in humans," in Medicine $i$ Fizkultura, pp. 387-406, State Publishing House, Sofia, Bulgaria, 1986.

[18] C. F. van Sumere, H. Teuchy, H. Pé, R. Verbeke, and J. Bekaert, "Quantitative investigation on the hippuric acid formation in healthy and diseased individuals," Clinica Chimica Acta, vol. 26, no. 1, pp. 85-88, 1969.

[19] G. Hammarsten, "On calcium oxalate and its solubility in the presence of inorganic salts with special reference to the occurrence of oxaluria," Comptes-Rendus des Travaux du Laboratoire Carlsberg, vol. 17, p. 1, 1921.

[20] P. Leskovar, "Methoden und techniken zum erfassen der kristalle in wassrigen losungen, unter besonderer berucksichtigung der problemstellugen in der harnsteinforschung," Aktuell Nephrologie, vol. 12, pp. 149-175, 1979.

[21] R. H. Doremus, S. Teich, and P. X. Silvis, "Crystallization of calcium oxalate from synthetic urine," Investigative Urology, vol. 15, no. 6, pp. 469-472, 1978.

[22] W. G. Robertson, M. Peacock, and B. E. Nordin, "Activity products in stone-forming and non-stone-forming urine," Clinical Science, vol. 34, no. 3, pp. 579-594, 1968.

[23] W. C. Thomas Jr., H. Marjorie, H. Malagodi, and O. M. Rennert, "Urinary excretion of amino acids by subjects with renal calculi," in Urolithiasis. Clinical and Basic Research, L. H. Smith, W. G. Robertson, and B. Finlayson, Eds., pp. 77-80, Plenum Press, London, UK, 1981.

[24] O. Budevsky, Foundation of Chemical Analysis, John Wiley \& Sons, New York, NY, USA, 1979.

[25] H. J. Binder, "Intestinal oxalate absorption," Gastroenterology, vol. 67, no. 3, pp. 441-446, 1974.

[26] M. Menon and C. J. Mahle, "Oxalate metabolism and renal caculi," Journal of Urology, vol. 127, no. 1, pp. 148-151, 1982.

[27] M. Sugita, H. Aikawa, K. Suzuki et al., "Urinary hippuric acid excretion in everyday life," Tokai Journal of Experimental and Clinical Medicine, vol. 13, no. 4-5, pp. 185-190, 1988.

[28] R. L. Gambardella and K. E. Richardson, "The pathways of oxalate formation from phenylalanine, tyrosine, tryptophan 
and ascorbic acid in the rat," Biochimica et Biophysica Acta, vol. 499, no. 1, pp. 156-168, 1977.

[29] V. Y. A. Kraevsky, Atlas of Microscopic Precipitates in Urine, Medicine Publishers, Moscow, Russia, 1976, (Russian).

[30] M. Allison, H. M. Cook, and D. B. Milne, "Oxalate degradation by gastrointestinal bacteria from humans," Journal of Nutrition, vol. 116 , no. 3, pp. 455-460, 1986.

[31] J. Hamilton-Miler, "Letters," Journal of the American Medical Association, vol. 272, p. 588, 1994.

[32] I. Gutzow, S. Atanassova, and K. Neykov, "Solubility and crystallization in biological fluids and the problems of life and health," Pure and Applied Chemistry, vol. 74, no. 10, pp. 17851792, 2002. 


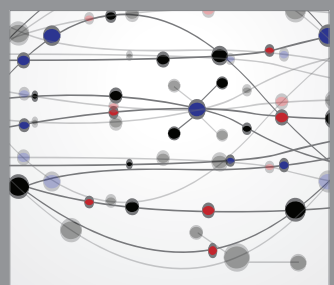

The Scientific World Journal
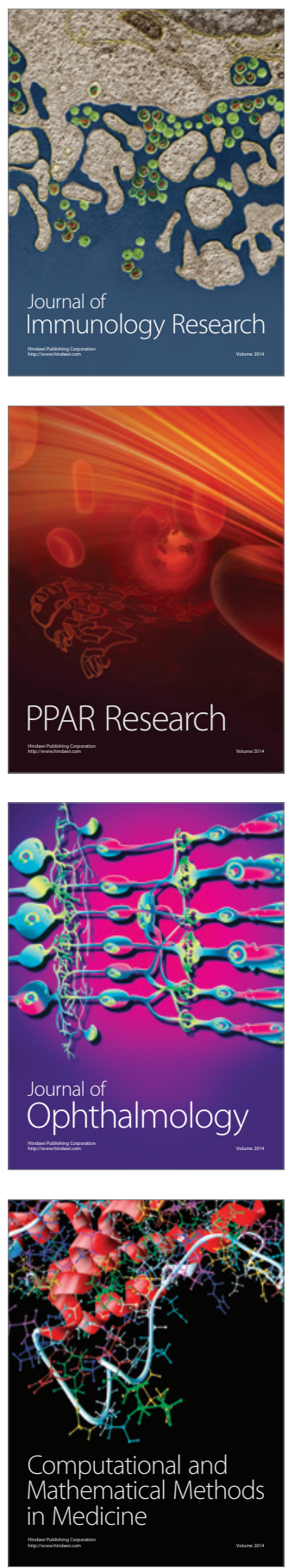

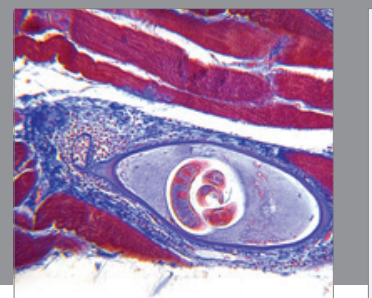

Gastroenterology

Research and Practice
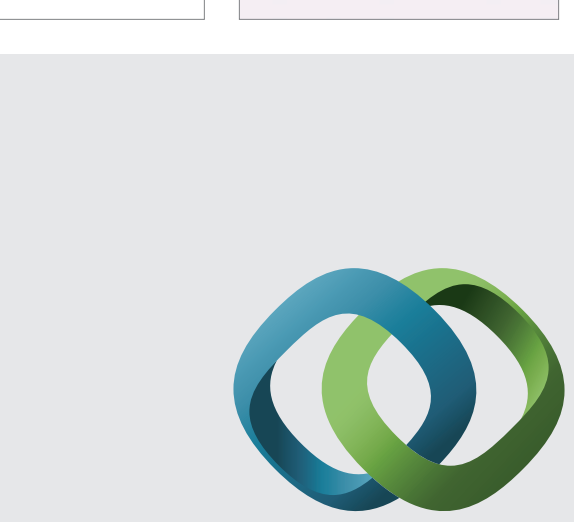

\section{Hindawi}

Submit your manuscripts at

http://www.hindawi.com
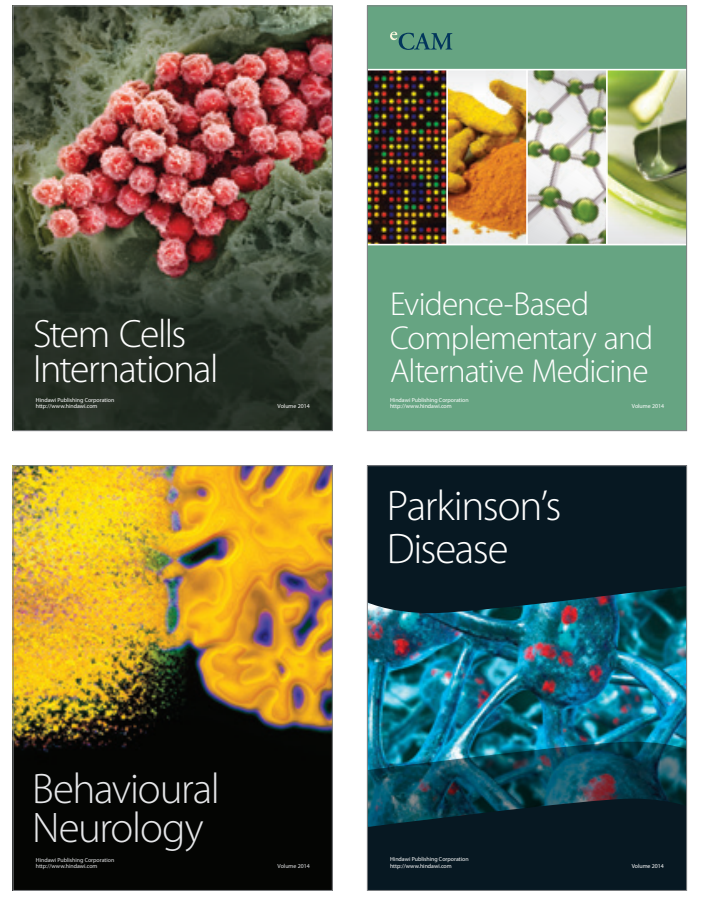
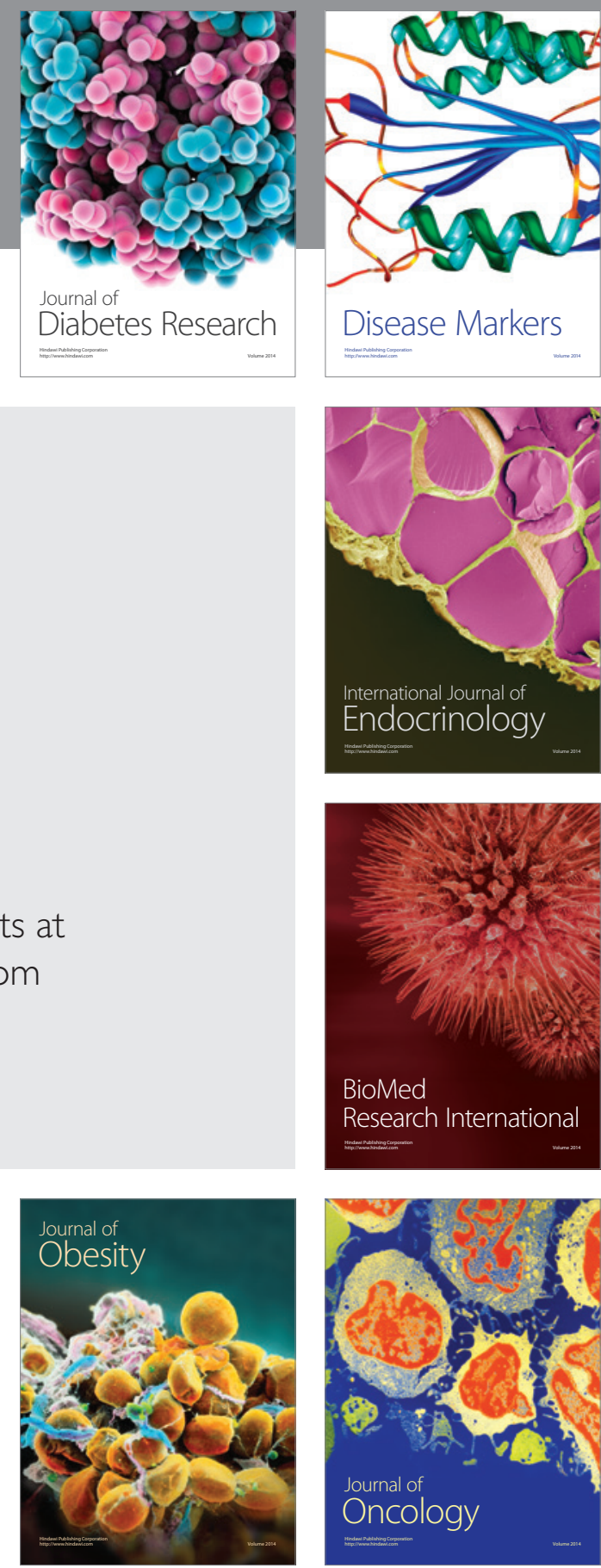

Disease Markers
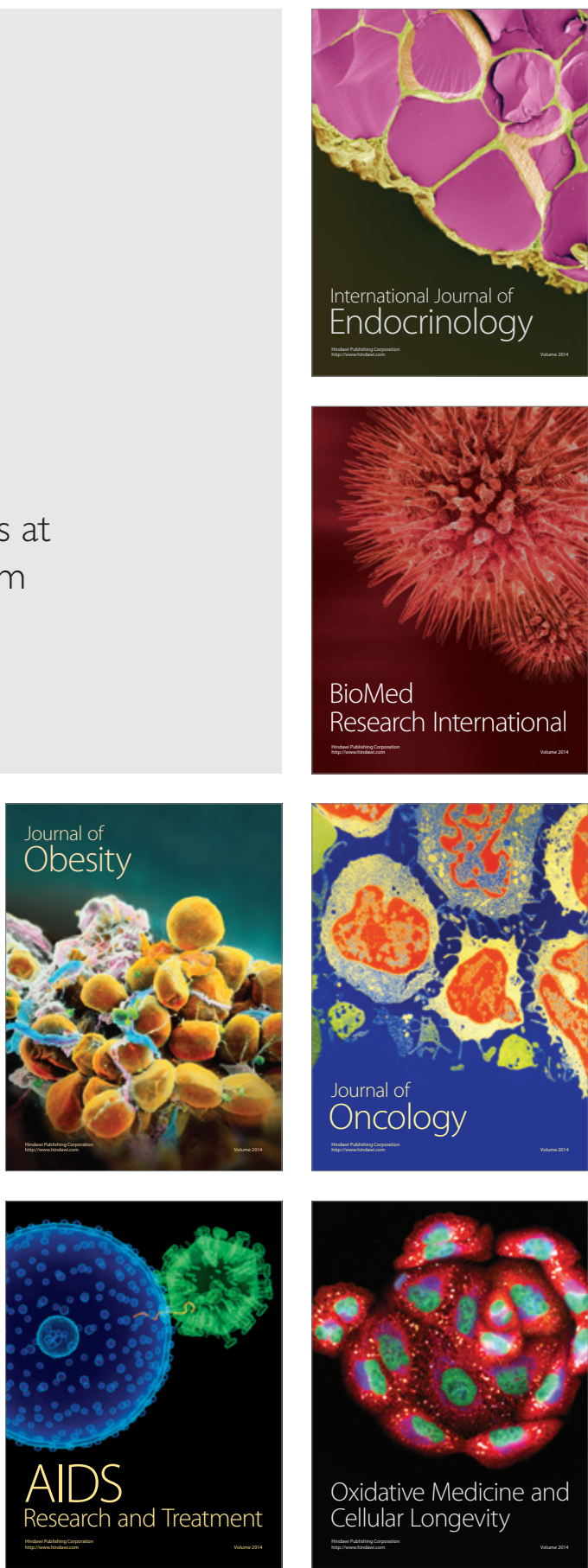